\title{
Individualized positioning for maximum heart protection during breast irradiation
}

\section{Zoltán Varga, Adrienn Cserháti, Ferenc Rárosi, Krisztina Boda, Gergely Gulyás, Zsófia Együd \& Zsuzsanna Kahán}

To cite this article: Zoltán Varga, Adrienn Cserháti, Ferenc Rárosi, Krisztina Boda, Gergely Gulyás, Zsófia Együd \& Zsuzsanna Kahán (2014) Individualized positioning for maximum heart protection during breast irradiation, Acta Oncologica, 53:1, 58-64, DOI: 10.3109/0284186X.2013.781674

To link to this article: $\underline{h t t p: / / d x . d o i . o r g / 10.3109 / 0284186 X .2013 .781674 ~}$

$$
\text { 曲 Published online: } 02 \text { Apr } 2013 .
$$

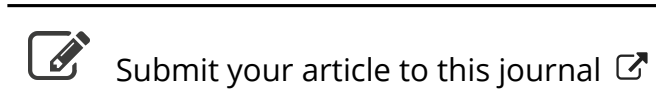

\footnotetext{
Џ Article views: 437
}

\section{Q View related articles ¿}

View Crossmark data ¿

7 Citing articles: 5 View citing articles 4 


\title{
Individualized positioning for maximum heart protection during breast irradiation
}

\author{
ZOLTÁN VARGA ${ }^{1}$, ADRIENN CSERHÁTI ${ }^{1}$, FERENC RÁROSI $^{2,3}$, KRISZTINA BODA ${ }^{2}$, \\ GERGELY GULYÁS ${ }^{4}$, ZSÓFIA EGYÜD ${ }^{1} \&$ ZSUZSANNA KAHÁN $^{1}$
}

${ }^{1}$ Department of Oncotherapy, University of Szeged, Szeged, Hungary, ${ }^{2}$ Department of Medical Physics and Informatics, University of Szeged, Szeged, Hungary, ${ }^{3}$ Bolyai Institute, University of Szeged, Szeged, Hungary and ${ }^{4}$ Institute of Informatics, University of Szeged, Szeged, Hungary

\begin{abstract}
Background. Prone positioning has been found feasible and appropriate for the reduction of radiation exposure of the lungs, but its effects on the heart dose remain controversial. Individual anatomical features were sought for the selection of optimal treatment positioning. Material and methods. In 138 left-sided breast cancer cases awaiting postoperative whole-breast radiotherapy, conformal radiotherapy plans were generated in both prone and supine positions. Results. The radiation doses to the left anterior descending coronary artery (LAD) and heart in the two positions differed individually, and were strongly related to the body mass index (BMI). Image fusion of the CT scans revealed that prone positioning was detrimental if the heart was situated distant from the chest wall in the supine position, but moved to the chest wall in the prone position. For characterization of the geography of the heart and the breast, the median distance between the LAD and the chest wall $\left(\mathrm{d}_{\text {median }}\right)$, and the heart area included in the radiation field on a single CT scan at the middle of the heart in the supine position $\left(\mathrm{A}_{\text {heart }}\right)$ proved most appropriate. Conclusion. A validated statistical model, utilizing the $B M I, d_{\text {median }}$ and $A_{\text {heart }}$, permits individualized positioning for maximum heart protection.
\end{abstract}

Although breast irradiation after surgery for breast cancer contributes to an improved survival, it may cause radiation sequelae of the heart [1]. The most significant changes leading to radiation-induced heart disease occur in the cardiac micro- and macrovasculature [2]. In left-sided cases, the left anterior descending coronary artery (LAD) is often situated in the tangential fields and regarded as an organ at risk (OAR) $[3,4]$.

Among other methods, individual positioning is a feasible approach through which to control the radiation dose to the OARs $[5,6]$. While prone positioning dramatically reduces the lung dose, reduction of the heart exposure is controversial [5-11]. Some studies indicated that prone positioning is preferable for heart protection in general [5], whereas others did not reveal a significant advantage of prone positioning over supine positioning in the overall population [7-10]. Three investigations demonstrated individual variability, but no specific patient-related feature was identified in favor of a particular treatment setup $[6,9,10]$. Others found an association between breast size and the benefit of prone positioning $[8,11]$.

In this prospective study, the goal was the identification of patient-related parameters via which to predict the preferable positioning mode for breast radiotherapy in clinical practice.

\section{Material and methods}

The study was approved by the Institutional Review Board of the University of Szeged, and all the enrolled patients gave their written informed consent to participation. Consecutive patients with left-sided breast cancer requiring radiotherapy of the operated breast were included throughout the study.

CT-based three-dimensional (3D) treatment planning $\left[\mathrm{XIO}^{\circledR}\right.$ (Elekta) vs. 4.2.0, convolution algorithm for photon dose calculation] was performed in both supine and prone positions, as detailed previously [7]; following the collection of dosimetric data, 
the treatment position chosen for radiotherapy was that which best spared the LAD and heart. The breast tissue was visualized on CT, and the clinical target volume was contoured at the chest wall/breast parenchyma interface, $4 \mathrm{~mm}$ from the skin, cranially the head of clavicle, medially the border of the sternum, laterally and caudally the visible breast parenchyma/connective tissue verge. $3 \mathrm{D}$ image reconstruction was used for checking delineation. Planning target volumes (PTVs) were generated by the addition of 3D 5-mm margins to the clinical target volume limited $4 \mathrm{~mm}$ from the skin. The heart and LAD were defined according to published recommendations [4,12] (Figure 1). Equivalent target and OAR volume contouring in either setup was ensured by one author $(\mathrm{ZK})$. Treatment plans were developed by applying conventional 6-MV tangential photon fields set up isocentrically, and a median of 2 (1-3) individually weighted 6/15-MV segmental fields superimposed on the tangential fields by using a multileaf collimator. A mean dose to the PTV of $50 \mathrm{~Gy}$ was aimed at. For the analysis of dose distribution, the volume receiving $95-107 \%$ of the total dose $\left(\mathrm{V}_{95-107 \%}\right)$, and the doses received by $5 \%$ and $95 \%$ of the PTV $\left(\mathrm{D}_{5 \%} / \mathrm{D}_{95 \%}\right)$, the healthy tissue conformity index (HTCI) and the conformation number (CN) were calculated using the following equations: HTCI $=\frac{T V_{R I}}{V_{R I}}$ and $\mathrm{CN}=\frac{T V_{R I}}{T V} \times \frac{T V_{R I}}{V_{R I}}$ (TV: Target volume, i.e. PTV; $\mathrm{TV}_{\mathrm{RI}}$ : Target volume covered by the reference isodose; $\mathrm{V}_{\mathrm{RI}}$ : Volume of the reference isodose) [13].

The radiation exposures of the OARs (the volume of the ipsilateral lung receiving $>20 \mathrm{~Gy}\left[\mathrm{~V}_{20 \mathrm{~Gy}}\right]$, the mean doses to the ipsilateral lung [MLD], LAD $\left[\mathrm{MD}_{\mathrm{LAD}}\right]$ and heart, the volume of the LAD recieving $>20$ Gy $\left[\mathrm{V}_{20 \mathrm{GyLAD}}\right]$, the volume of the heart receiving $>25$ Gy $\left[\mathrm{V}_{25 \text { Gyheart }}\right]$, and the volume of the contralateral breast receiving $>5$ Gy $\left.\left[\mathrm{V}_{5 \mathrm{~Gy}}\right]\right)$, were registered in both positions. The advantage of the prone over the supine position was analyzed in terms of the differences between $\mathrm{MD}_{\mathrm{LAD}}$ and $\mathrm{V}_{25 \mathrm{~Gy}-}$ heart in the two positions $\left(\Delta \mathrm{MD}_{\mathrm{LAD}}\right.$ and $\left.\Delta \mathrm{V}_{25 \mathrm{Gyheart}}\right)$ in relation to the patient characteristics (the breast volume and the body mass index [BMI]).

In order to compare the geographies of the index breast, the heart and the LAD in the two positions, corresponding CT images acquired in the supine and prone positions were fused within the radiotherapy planning system. Perfect 3D image fusion was aimed at in the horizontal, sagittal and coronal planes. As the most important geographical pivots of breast radiotherapy planning, the sternum and anterior chest wall were selected to corroborate the adequacy of image matching. The image fusion indicated that the heart was situated at individual distances from the chest wall in the supine position, whereas in the prone position it almost always lay adjacent to the chest wall (Figure 2). The median of the shortest distances between the anterior surface of the LAD and the chest wall representing the middle of the LAD $\left(\mathrm{d}_{\text {median }}\right)$ and the area of the heart (measured with the DicomWorks vs. 1.3.5 software) in the radiation field on the same CT scan in the supine position $\left(\mathrm{A}_{\text {heart }}\right)$ typified the anatomical situation (Figure 1a insert).

Correlation-regression analysis, paired and independent sample t-tests, receiver operating characteristics (ROC) analyses, multivariate logistic regression and multiple linear regression models were used. The separability of the dataset was verified through artificial intelligence classification methods: Support Vector Machine (SVM) with dot kernel and Neural Net with one hidden layer $[14,15]$. Classification methods were trained on 83 cases and validated on a set of 55 further cases. A 1000-times random cross-validation method was applied to the overall dataset. Sensitivity and specificity were calculated with supine positioning as positive determinant in the model.
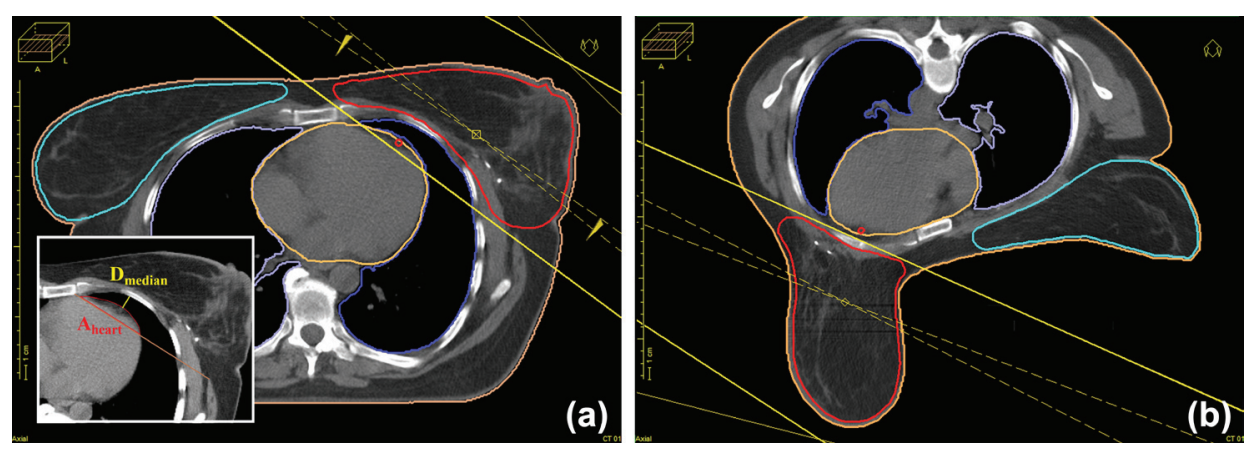

Figure 1. Typical PTV and OAR contouring and field setup in the supine (a) and prone (b) positions. The shortest distance between the anterior surface of the LAD and the chest wall $\left(\mathrm{d}_{\text {median }}\right)$ and the surface area of the heart in the radiation field $\left(\mathrm{A}_{\text {heart }}\right)$ are measured at the middle of the LAD in the supine position (insert). 

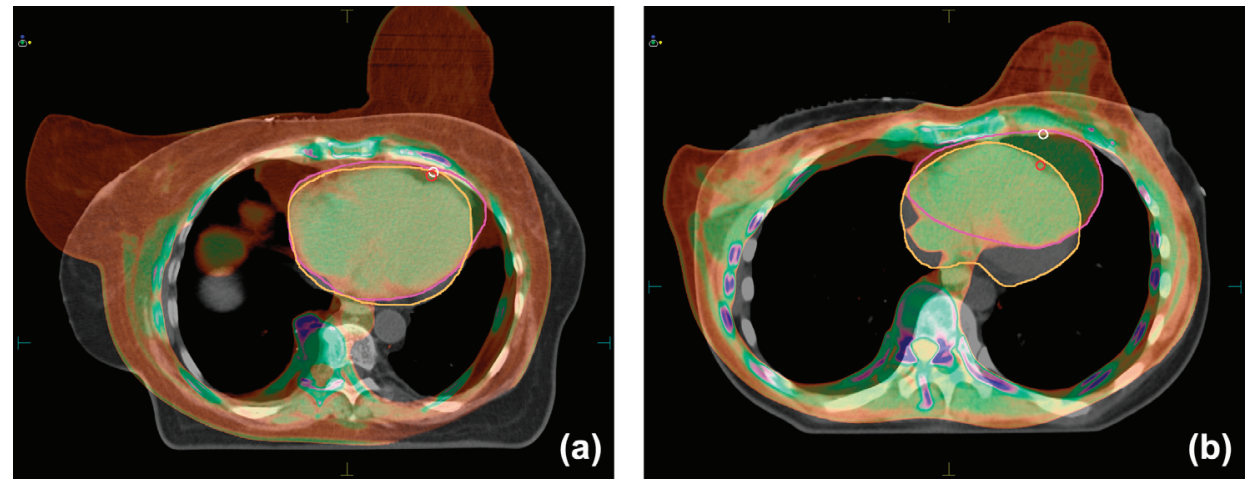

Figure 2. Image fusion of the CT scans acquired in the prone versus the supine position illustrates that, if the heart is adjacent to the chest wall in both positions, the prone position helps prevent heart exposure through separation of the breast from the chest wall (a); if the heart is distant from the chest wall in the supine position, the dose to the heart is increased due to its shift to the chest wall in the prone position (b). (greyscale: supine, color: prone).

\section{Results}

\section{Heart and LAD doses}

Table I shows the baseline characteristics of the two cohorts of patients included in the entire study; there was no significant difference between the two groups. In the population of the first 83 patients (training set), the mean values of the radiation doses to the ipsilateral lung, LAD and heart were significantly lower in the prone than in the supine position (Table II); the dose homogeneity was worse, but the HTCI and CN values indicated that less healthy tissue was exposed to radiation in the prone position (Table III). $\Delta \mathrm{MD}_{\mathrm{LAD}}$ and $\Delta \mathrm{V}_{25 \mathrm{Gyheart}}$ displayed individual differences: in about half of the patients, the radiation dose to the heart was lower in the prone position; in the others, it was higher or not significantly different (Figure 3). In $40 \%$ and $19 \%$ of the patients, respectively, $\mathrm{MD}_{\mathrm{LAD}}$ and $\mathrm{V}_{25 \text { Gyheart }}$ were significantly higher in the prone position. The doses to the LAD and the heart were both lower in the supine position in 22 cases, and both lower in the prone position in 45 cases, while in 16 cases the results were discordant: from the aspect of the LAD dose, 14 cases favored supine positioning, and two cases prone positioning.

\section{The effect of the BMI}

The difference in heart or LAD doses in the prone versus supine position did not differ according to whether the volume of the operated breast was $<$ or $\geq$ the median value of $900 \mathrm{~cm}^{3}$ (Figure 3). In ROC analyses and multivariate analyses including the $\mathrm{BMI}$, the PTV and the heart volume, the BMI gave the best results for $\Delta \mathrm{MD}_{\mathrm{LAD}}$ and $\Delta \mathrm{V}_{25 \text { Gyheart }}$ (Table IV); ROC curve analysis indicated that patients with $B M I \geq 26.3 \mathrm{~kg} / \mathrm{m}^{2}$ benefited most from prone positioning. In the multivariate logistic regression models relating to the benefit of prone positioning, only the BMI remained significant. The likelihood of a one unit increase in $\Delta M D_{\mathrm{LAD}}$ and $\Delta \mathrm{V}_{25 \text { Gyheart }}$ for prone versus supine positioning was increased, with $\mathrm{OR}=1.256(1.103-1.430, \mathrm{p}=0.001)$ and $\mathrm{OR}=1.404$ (95\% CI 1.180-1.672, $\mathrm{p}<0.001)$, respectively, for every $1 \mathrm{~kg} / \mathrm{m}^{2}$ increase in BMI.

\section{The effect of the anatomical variables}

Since the volumes of the breast $(R=0.681, p<0.001)$ and heart $(\mathrm{R}=0.440, \mathrm{p}<0.001)$ correlated significantly with the BMI, we postulated that the BMI is a resultant of the variables that determine the position and size of the target volume and the OARs, and

Table I. Baseline characteristics of the patients included in the study $(n=138)$.

\begin{tabular}{|c|c|c|c|c|c|c|}
\hline \multirow[b]{2}{*}{ Variable } & \multicolumn{3}{|c|}{ Training set $(\mathrm{n}=83)$} & \multicolumn{3}{|c|}{ Validation set $(n=55)$} \\
\hline & Median & Mean \pm SE & Range & Median & Mean \pm SE & Range \\
\hline Age (years) & 60.2 & $59.4 \pm 1.1$ & $31.1-79.1$ & 59.1 & $58.4 \pm 1.4$ & $26.0-76.5$ \\
\hline Weight (kg) & 73.0 & $73.4 \pm 1.4$ & $46.0-112.0$ & 75.0 & $77.1 \pm 1.9$ & $49.0-120.0$ \\
\hline Height (cm) & 162.0 & $162.4 \pm 0.7$ & $149.0-178.0$ & 162.0 & $161.1 \pm 0.8$ & $140.0-179.0$ \\
\hline BMI $\left(\mathrm{kg} / \mathrm{m}^{2}\right)$ & 27.5 & $27.8 \pm 0.5$ & $17.1-38.9$ & 28.4 & $29.7 \pm 0.7$ & $20.3-44.1$ \\
\hline Breast volume $\left(\mathrm{cm}^{3}\right)$ & 897.0 & $983.1 \pm 46.8$ & $197.0-2448.0$ & 1061.0 & $1050.6 \pm 65.1$ & $257.0-2838.0$ \\
\hline Heart volume $\left(\mathrm{cm}^{3}\right)$ & 515.0 & $522.0 \pm 11.6$ & $307.0-965.0$ & 540.0 & $553.5 \pm 14.7$ & $360.0-862.0$ \\
\hline $\mathrm{d}_{\text {median }}(\mathrm{cm})$ & 1.3 & $1.33 \pm 0.1$ & $0.4-2.2$ & 1.4 & $1.39 \pm 0.1$ & $0.3-3.3$ \\
\hline $\mathrm{A}_{\text {heart }}\left(\mathrm{mm}^{2}\right)$ & 549.0 & $599.9 \pm 43.9$ & $0-1820.0$ & 455.0 & $476.9 \pm 50.0$ & $0-1627.0$ \\
\hline
\end{tabular}


Table II. Radiation doses to the OARs. Mean values \pm SE are shown.

\begin{tabular}{|c|c|c|c|c|c|c|c|}
\hline \multirow[b]{2}{*}{$\mathrm{n}=83$} & \multicolumn{2}{|c|}{ LAD } & \multicolumn{2}{|c|}{ Heart } & \multicolumn{2}{|c|}{ Ipsilateral lung } & \multirow{2}{*}{$\frac{\text { Contralateral breast }}{\mathrm{V}_{5 \mathrm{~Gy}}(\%)}$} \\
\hline & Mean dose (Gy) & $\mathrm{V}_{20 \mathrm{~Gy}}(\%)$ & Mean dose (Gy) & $\mathrm{V}_{25 \mathrm{~Gy}}(\%)$ & MLD (Gy) & $\mathrm{V}_{20 \mathrm{~Gy}}(\%)$ & \\
\hline Prone & $11.06 \pm 0.79$ & $21.91 \pm 2.18$ & $2.18 \pm 0.15$ & $2.01 \pm 0.25$ & $0.99 \pm 0.18$ & $1.33 \pm 0.23$ & $1.57 \pm 0.25$ \\
\hline Supine & $13.70 \pm 0.79$ & $29.26 \pm 1.98$ & $2.89 \pm 0.19$ & $3.54 \pm 0.37$ & $6.29 \pm 0.29$ & $11.87 \pm 0.61$ & $1.07 \pm 0.32$ \\
\hline $\mathrm{p}^{*}$ & 0.014 & 0.010 & 0.001 & $<0.001$ & $<0.001$ & $<0.001$ & 0.154 \\
\hline
\end{tabular}

*paired t-test

their relationship. We therefore studied the situation of the operated breast and the heart via image fusion of the prone and supine CT scans. When BMI $\geq 26.3$ $\mathrm{kg} / \mathrm{m}^{2}$, the heart usually lay adjacent to the chest wall in both positions, and removal of the breast from the chest wall to the hanging position involved a radiation field geometry change and a heart dose reduction (Figure 2a). When $\mathrm{BMI}<26.3 \mathrm{~kg} / \mathrm{m}^{2}$, the heart was situated distant from the chest wall, but fell many centimeters anterior in the prone position, usually directly to the chest wall, which favored an increased heart exposure, despite the separation of the breast from the chest wall (Figure 2b). For quantitative characterization, $\mathrm{d}_{\text {median }}$ and $\mathrm{A}_{\text {heart }}$ were selected (Figure 1a insert). $d_{\text {median }}$ proved to correlate inversely with $\Delta \mathrm{V}_{25 \text { Gyheart }}(\mathrm{R}=-0.477, \mathrm{p}<0.001)$, $\Delta \mathrm{MD}_{\mathrm{LAD}}(\mathrm{R}=-0.567, \mathrm{p}<0.001), \mathrm{A}_{\text {heart }}(\mathrm{R}=-0.424$, $\mathrm{p}<0.001)$ and the BMI $(\mathrm{R}=-0.344, \mathrm{p}<0.001)$.

\section{Predictive model}

None of these predictors alone resulted in a good classification, and linear regression models were therefore developed from these anatomical features and the BMI for the prediction of optimal positioning, with $\Delta \mathrm{MD}_{\mathrm{LAD}}$ and $\Delta \mathrm{V}_{25 \text { Gyheart }}$ as dependent variables. A good classification of the cases (depending on the choice of cut-off point) was achieved, based on the estimated dose differences. With a single cut-off point, a case was classified to prone positioning when the predicted value exceeded the cut-off point. Based on the data of the first 83 cases, reasonable sensitivity and specificity values were verified (Table $\mathrm{V}$ ).

The correctness of the model was checked in various ways: 1) In a validation set of 55 cases, the sensitivity and specificity were $72.2 \%$ and $89.2 \%$ for $\Delta \mathrm{MD}_{\mathrm{LAD}}$, and $90.2 \%$ and $35.7 \%$ for $\Delta \mathrm{V}_{25 \text { Gyheart }}$, respectively; 2) In a 1000-times random crossvalidation procedure on the dataset from the 138 cases, both the proportion of misclassified patients and the extent of misclassification were assessed via the dose difference (Table $\mathrm{V}$ ): for $\Delta \mathrm{MD}_{\mathrm{LAD}}$ a threshold of $0.9 \mathrm{~Gy}$, and for $\Delta \mathrm{V}_{25 \mathrm{Gyheart}}$ a cut-off point of $0.75 \%$ seemed preferable; 3 ) For the overall dataset with the SVM artificial intelligence model, the sensitivity and specificity were $81.0 \%$ and $87.0 \%$ $\left(\Delta \mathrm{MD}_{\mathrm{LAD}}\right)$ and $88.1 \%$ and $55.3 \%\left(\Delta \mathrm{V}_{25 \text { Gyheart }}\right)$, respectively; with Neural Net they were $85.7 \%$ and $76.0 \%\left(\Delta \mathrm{MD}_{\mathrm{LAD}}\right)$ and $88.0 \%$ and $60.5 \%\left(\Delta \mathrm{V}_{25 \text { Gyheart }}\right)$, respectively.

\section{Discussion}

We have demonstrated that, although prone positioning dramatically reduces the dose to the lung, it increases the LAD and heart doses in a significant proportion of the cases. The geometries of the heart, chest wall and breast are the most important determinants of the cardiac dose. For consideration of the patient's anatomic variables, a supine CT scan seems preferable. The BMI additionally facilitates the choice of treatment setup via rough orientation, or its use in a predictive model. As a tool for individualized heart protection in clinical practice, the model based on BMI, $d_{\text {median }}$ and $A_{\text {heart }}$ ensures good sensitivity and specificity.

For calculation of the heart dose in the prone versus supine treatment setup, different approaches have been implemented. In 51 IMRT cases $[5,16]$, and in a series of 200 patients treated with conformal radiotherapy $[6,17]$, the in-field heart volume served as a surrogate marker of radiation heart exposure. Other investigations have used conformal radiotherapy and either $\mathrm{V}_{20 \mathrm{~Gy}}[9]$ or $\mathrm{V}_{30 \mathrm{~Gy}}[9,10]$. In their pioneering study of the LAD and heart doses, Kirby et al.

Table III. Dose homogeneity and conformity according to the treatment position $(\mathrm{p}<0.001$ in all cases).

\begin{tabular}{lcccc}
\hline & $\begin{array}{l}\mathrm{V}_{95 \%-107 \%} \\
(\%, \text { mean } \pm \mathrm{SE})\end{array}$ & $\begin{array}{c}\mathrm{D}_{5 \%} / \mathrm{D}_{95 \%} \\
(\mathrm{mean} \pm \mathrm{SE})\end{array}$ & $\begin{array}{c}\text { Healthy tissue conformation } \\
\text { index }(\mathrm{HTCI})(\text { mean } \pm \mathrm{SE})\end{array}$ & $\begin{array}{c}\text { Conformation number } \\
(\mathrm{CN})(\text { mean } \pm \mathrm{SE})\end{array}$ \\
\hline Supine & $91.30 \pm 7.48$ & $1.10 \pm 0.09$ & $0.80 \pm 0.06$ & $0.58 \pm 0.05$ \\
Prone & $88.34 \pm 7.24$ & $1.14 \pm 0.09$ & $0.940 \pm 0.08$ & $0.682 \pm 0.06$ \\
\hline
\end{tabular}



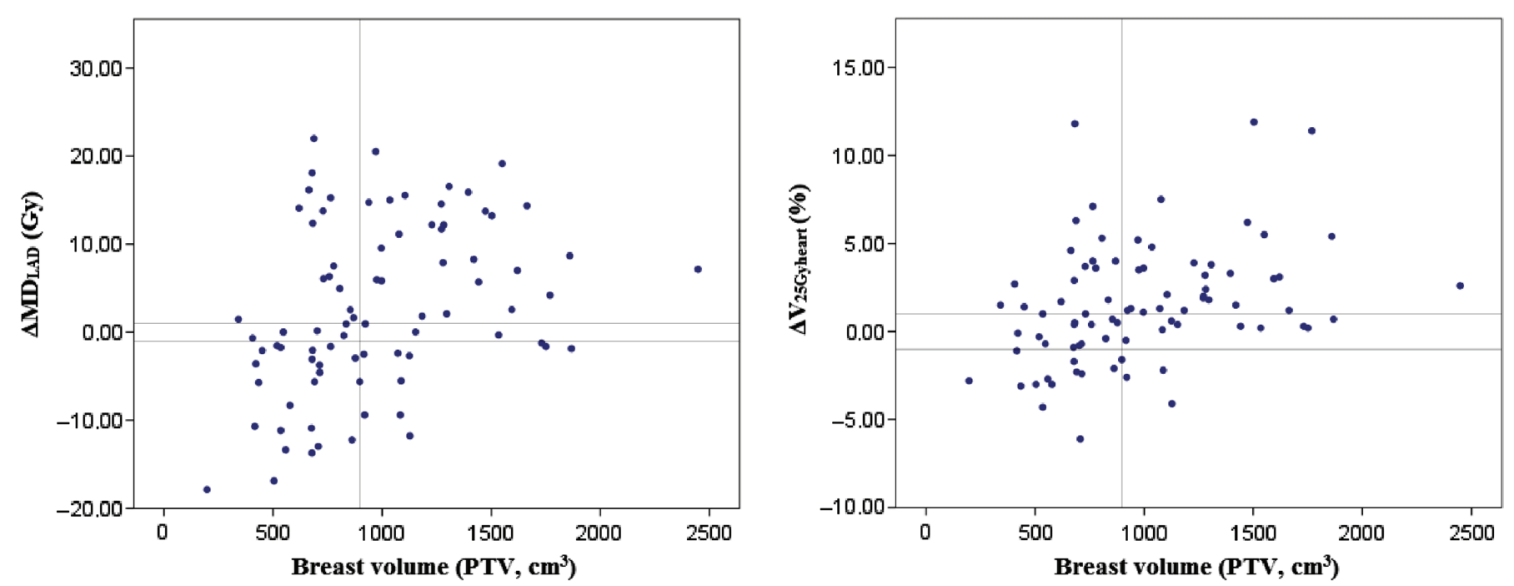

Figure 3. Benefit of the prone position (the difference in LAD and heart doses between the prone and supine treatment positions) in the overall population of 83 patients as a function of breast size (LAD: $\Delta \mathrm{MD}_{\mathrm{LAD}}$, heart: $\Delta \mathrm{V}_{25 \mathrm{Gyheart}}$ ). The vertical line indicates the median PTV value of $900 \mathrm{~cm}^{3}$, the horizontal lines indicate the dose differences regarded as clinically not significant, $\pm 1 \mathrm{~Gy}(\mathrm{MD}$ LAD $)$ and $\pm 1 \%$ $\left(\mathrm{V}_{25 \text { Gyheart }}\right)$.

[8] analyzed the mean heart dose, whereas we preferred $\mathrm{V}_{25 \text { Gyheart }}$ for the assessment of the high-dose volume of the heart. In fact, this measure was shown to correlate with increased cardiac mortality $[18,19]$, and has been used as an indicator of heart dose in more recent studies too [20,21]. For the LAD, because of its very small volume, we considered the $M D_{\text {LAD }}$ appropriate. Our results on the LAD dose in 138 cases are comparable with those of Kirby et al. [8].

The proportion of patients with lower heart exposure in the prone than in the supine position varies. As concerns the in-field heart volume, Lymberis et al. found that $46(87 \%)$ of 53 left breast cancer patients benefited from prone positioning, while the supine position was preferable in only five cases $(10 \%)$ [11]. Kirby et al. [8] concluded that prone positioning reduced the heart and LAD doses in about two-thirds of the patients, but was detrimental in approximately one-third of the cases, as regards the mean doses to both the LAD and the heart. Formenti et al. [6] demonstrated that the in-field volume of the heart was reduced in the prone position in $85 \%$ of the cases. Relative to all of the reported studies, we found a higher proportion of patients who benefited from supine positioning: in $40 \%$ and $19 \%$ of the patients, the dose to the LAD or heart, respectively, was significantly lower in the supine than in the prone position. The underlying causes of this difference might include the methods and indicators we used. The relatively high number of our cases with a preferable LAD dose in the supine position draws attention to the need for a refined comprehensive OAR protection approach. The strength of our study is that it provided robust dose-volume data on both the heart and the LAD. The reliability of the findings is supported by the use of justified methods (equivalent volumes of target and OARs in the two positions), and the consistency regarding the sensitivity and specificity of the model.

The question of which OAR is most important as concerns radiation-induced heart damage remains unanswered. The clinical results indicate that the high-dose volume of the heart is the key determinant of the long-term outcome, but the apparently logical role of the LAD has not been completely clarified [1-4]. The situation is further complicated by the finding that those who gain from prone positioning through heart protection are not always those who benefit through LAD exposure. The proportion of

Table IV. ROC curve analyses of selected patient characteristics $(n=83)$ as predictors of the benefit of prone positioning for heart protection during breast radiotherapy.

\begin{tabular}{lcc}
\hline & AUC MD $_{\text {LAD }} \pm$ SE & AUC $_{25 \text { Gyheart }} \pm$ SE \\
\hline Weight & $0.692 \pm 0.061(\mathrm{p}=0.003)$ & $0.793 \pm 0.056(\mathrm{p}<0.001)$ \\
Height & $0.370 \pm 0.062(\mathrm{p}=0.043)$ & $0.417 \pm 0.068(\mathrm{p}=0.238)$ \\
BMI & $0.740 \pm 0.056(\mathrm{p}<0.001)$ & $0.825 \pm 0.054(\mathrm{p}<0.001)$ \\
Breast volume $(\mathrm{PTV})$ & $0.722 \pm 0.058(\mathrm{p}=0.001)$ & $0.813 \pm 0.047(\mathrm{p}<0.001)$ \\
Heart volume & $0.652 \pm 0.062(\mathrm{p}=0.018)$ & $0.661 \pm 0.064(\mathrm{p}=0.022)$ \\
$\mathrm{d}_{\text {median }}$ & $0.785 \pm 0.050(\mathrm{p}<0.001)$ & $0.730 \pm 0.060(\mathrm{p}=0.001)$ \\
$\mathrm{A}_{\text {heart }}$ & $0.868 \pm 0.039(\mathrm{p}<0.001)$ & $0.852 \pm 0.050(\mathrm{p}<0.001)$ \\
\hline
\end{tabular}


Table V. Classification measures for $\Delta \mathrm{MD}_{\mathrm{LAD}}$ and $\Delta \mathrm{V}_{25 \text { Gyheart }}$ using a single discrimination threshold.

\begin{tabular}{cccccc}
\hline & $\begin{array}{c}\text { Cut-off point } \\
\text { (Gy) }\end{array}$ & $\begin{array}{c}\text { Sensitivity } \\
(\%)\end{array}$ & $\begin{array}{c}\text { Specificity } \\
(\%)\end{array}$ & $\begin{array}{c}\text { Extent of wrong } \\
\text { estimation, decision: } \\
\text { prone (Gy, mean } \pm \text { SD) }\end{array}$ & $\begin{array}{c}\text { Extent of wrong } \\
\text { estimation, decision: } \\
\text { supine (Gy, mean } \pm \text { SD) }\end{array}$ \\
\hline$\Delta$ MD $_{\text {LAD }}$ (Gy) & -0.6 & 66.6 & 91.1 & $2.5 \pm 3.9$ & $-0.7 \pm 1.0$ \\
& -0.3 & 70.8 & 90.7 & $2.6 \pm 3.6$ & $-0.8 \pm 1.1$ \\
& 0 & 74.4 & 90.0 & $2.4 \pm 3.4$ & $-0.9 \pm 1.3$ \\
& 0.3 & 77.7 & 88.9 & $2.1 \pm 3.0$ & $-1.2 \pm 1.6$ \\
& 0.6 & 80.7 & 87.5 & $1.7 \pm 2.6$ & $-1.7 \pm 1.9$ \\
& 0.9 & 83.4 & 86.0 & $1.5 \pm 2.4$ & $-2.0 \pm 2.2$ \\
& 1.2 & 85.4 & 83.6 & $1.1 \pm 2.3$ & $-2.3 \pm 2.8$ \\
& 1.5 & 86.5 & 81.7 & $1.1 \pm 2.2$ & $-3.0 \pm 3.7$ \\
& 1.8 & 86.8 & 79.9 & $1.3 \pm 2.3$ & $-3.5 \pm 4.2$ \\
& 0 & 47.9 & 89.7 & $1.19 \pm 1.43$ & $-0.39 \pm 0.47$ \\
& 0.25 & 56.2 & 88.8 & $1.14 \pm 1.40$ & $-0.47 \pm 0.52$ \\
& 0.50 & 63.2 & 85.9 & $1.05 \pm 1.40$ & $-0.52 \pm 0.52$ \\
& 0.75 & 72.4 & 82.4 & $0.86 \pm 1.37$ & $-0.54 \pm 0.82$ \\
1 & 78.8 & 77.7 & $0.82 \pm 1.43$ & $-0.65 \pm 0.94$ \\
& 1.25 & 84.0 & 74.0 & $0.75 \pm 1.47$ & $-0.75 \pm 0.96$ \\
1.50 & 87.4 & 77.0 & $0.71 \pm 1.51$ & $-0.98 \pm 1.05$ \\
& 1.75 & 89.9 & 62.1 & $0.63 \pm 1.17$ & $-1.14 \pm 1.24$ \\
\hline
\end{tabular}

our cases with such discordant results was $19 \%$; it is noteworthy that $\triangle \mathrm{MD}_{\mathrm{LAD}}$ was significantly smaller in these cases than in the concordant cases (data not shown). A similar disagreement of heart and LAD data was described by Kirby et al. [8], and Aznar et al. [22] reported that $8 / 24$ patients irradiated in the supine position received high LAD doses despite the heart doses not exceeding the dose constraint.

We consider that the LAD dose is of prime interest: 1) Irradiation of the LAD has more significant consequences than irradiation of a small part of the myocardium $[1,2] ; 2)$ The LAD, situated on the anterior surface of the myocardium, closest to the radiation beam, may be regarded as a surrogate indicator of the radiation harm. Further, the systematic displacement of the heart by the prone setup is greatest at the supero-lateral aspect of the heart [23], where the LAD runs. Kirby et al. [8] observed that only patients in whom the breast tissue is pulled anteriorly are likely to gain from prone treatment. In contrast, we found that only patients whose heart lay adjacent to the chest wall in both positions were likely to gain from the prone position, because the separation of the breast from the chest wall could prevent heart irradiation in these cases. Our strategy in individual cases is to consider the LAD dose first, then $\mathrm{V}_{25 \text { Gyheart }}$, and finally the lung dose. Since the acquisition of two sets of CT to compare the dosimetry in the two positions contravenes radiationhygienic and economic principles, we are aware of the need for a simple method for routine practice. In fact, different approaches have been reported as clinical tools for prediction of the preferable patient setup. Kirby et al. [8] concluded that prone positioning may be detrimental in left-sided breast cancer patients with small breasts. In a group of 198 patients where no valid classifier, including the breast size, was identified, Zhao et al. [17] developed a two-step decision-analysis algorithm using a weighted SVM. Based on the anatomical features detected on a prone CT series, this classified patients to prone radiotherapy or to a second CT in the supine position for comparison. Their strategy is in contrast with ours: with CT in all cases in the prone position first, the strongest determinant of the benefit in the supine setup, i.e. the distance between the heart and the chest wall, is missed. We identified three relevant anatomical features that characterize the size and geography of the index breast and the OARs, and developed a stable statistical model that we validated in 138 cases. With the aim of easy acquisition of these decisive data (and the avoidance of two CT series), we are currently testing a simple clinical method. A single CT slice image representing the middle of the heart is acquired by using the AP scout view in the supine position for the selection of the correct transversal plane. On that $C T$ scan, $\mathrm{d}_{\text {median }}$ and $\mathrm{A}_{\text {heart }}$ are measured after placing a straight line between the back muscle and the lateral edge of the sternum, representing the posterior edge of the radiation fields; the initial experience as concerns finding the correct slice, and using the data coming from it, is promising.

Interestingly, in a prospective study of 108 patients with negative pre-radiotherapy myocardial perfusion scans, an independent risk factor of developing perfusion defects during the follow-up period was found a $B M I \geq 25 \mathrm{~kg} / \mathrm{m}^{2}$, probably involving larger doses to the critical structures of the heart during radiotherapy in the supine position [24]. In a recent analysis 
of 100 radiotherapy plans in the supine position, among different patient-related features, the BMI was found the only independent predictor of 'suboptimal heart anatomy' defined as a $V_{25 \text { Gy heart }} \geq 6 \%$ involving increased risk of radiation-induced coronary artery disease [20]. Although the BMI has been found useful for rough orientation in our practice, the threshold of $26.3 \mathrm{~kg} / \mathrm{m}^{2}$ may not be most appropriate for the selection of those who benefit most from prone positioning in other populations.

In summary, the main outcomes of our study are a clarification of the interplay of various patientrelated parameters that influence the exposure of the different structures of the heart during breast radiotherapy in the prone and supine positions, and the development of a practical tool for prediction of the preferable treatment setup in individual patients. Naturally, our results need independent validation.

Declaration of interest: The authors report no conflicts of interest. The authors alone are responsible for the content and writing of the paper.

\section{References}

[1] McGale P, Darby SC, Hall P, Adolfsson J, Bengtsson NO, Bennet $\mathrm{AM}$, et al. Incidence of heart disease in 35,000 women treated with radiotherapy for breast cancer in Denmark and Sweden. Radiother Oncol 2011;100:167-75.

[2] Andratschke N, Maurer J, Molls M, Trott KR. Late radiation-induced heart disease after radiotherapy. Clinical importance, radiobiological mechanisms and strategies of prevention. Radiother Oncol 2011;100:160-6.

[3] Nilsson G, Holmberg L, Garmo H, Duvernoy O, Sjögren I, Lagerqvist $\mathrm{B}$, et al. Distribution of coronary artery stenosis after radiation for breast cancer. J Clin Oncol 2012;30: 380-6.

[4] Feng M, Moran JM, Koelling T, Chughtai A, Chan JL, Freedman BL, et al. Development and validation of a heart atlas to study cardiac exposure to radiation following treatment for breast cancer. Int J Radiat Oncol Biol Phys 2011;79:10-8.

[5] Formenti SC, Gidea-Addeo D, Goldberg JD, Roses DF, Guth A, Rosenstein BS, et al. Phase I-II trial of prone accelerated intensity modulated radiation therapy to the breast to optimally spare normal tissue. J Clin Oncol 2007;25:2236-42.

[6] Formenti SC, DeWyngaert JK, Jozsef G, Goldberg JD. Prone vs supine positioning for breast cancer radiotherapy. JAMA 2012;308:861-3.

[7] Varga Z, Hideghéty K, Mezö T, Nikolényi A, Thurzó L, Kahán Z. Individual positioning: A comparative study of adjuvant breast radiotherapy in the prone versus supine position. Int J Radiat Oncol Biol Phys 2009;75:94-100.

[8] Kirby AM, Evans PM, Donovan EM, Convery HM, Haviland JS, Yarnold JR. Prone versus supine positioning for whole and partial-breast radiotherapy: A comparison of nontarget tissue dosimetry. Radiother Oncol 2010;96:178-84.

[9] Griem KL, Fetherston P, Kuznetsova M, Foster GS, Shott S, Chu J, et al. Three-dimensional photon dosimetry:
A comparison of treatment of the intact breast in the supine and prone position. Int J Radiat Oncol Biol Phys 2003; 57:891-9.

[10] Buijsen J, Jager JJ, Bovendeerd J, Voncken R, Borger JH, Boersma LJ, et al. Prone breast irradiation for pendulous breasts. Radiother Oncol 2007;82:337-40.

[11] Lymberis SC, Dewyngaert JK, Parhar P, Chhabra AM, Fenton-Kerimian M, Chang J, et al. Prospective assessment of optimal individual position (prone versus supine) for breast radiotherapy: Volumetric and dosimetric correlations in 100 patients. Int J Radiat Oncol Biol Phys 2012; 84:902-9.

[12] Taylor CW, Povall JM, McGale P, Nisbet A, Dodwell D, Smith JT, et al. Cardiac dose from tangential breast cancer radiotherapy in the year 2006. Int J Radiat Oncol Biol Phys 2008;72:501-7.

[13] Feuvret L, Noël G, Mazeron JJ, Bey P. Conformity index: A review. Int J Radiat Oncol Biol Phys 2006;64:333-42.

[14] Chang RF, Wu WJ, Moon WK, Chou YH, Chen DR. Support vector machines for diagnosis of breast tumors on US images. Acad Radiol 2003;10:189-97.

[15] Bishop CM. Neural networks. In: Bishop CM, editor. Pattern recognition and machine working, 1st ed. NewYork: Springer; 2006. p. 225-90.

[16] DeWyngaert JK, Jozsef G, Mitchell J, Rosenstein B, Formenti SC. Accelerated intensity-modulated radiotherapy to breast in prone position: Dosimetric results. Int J Radiat Oncol Biol Phys 2007;68:1251-9.

[17] Zhao X, Wong EK, Wang Y, Lymberis S, Wen B, Formenti S, et al. A support vector machine (SVM) for predicting preferred treatment position in radiotherapy of patients with breast cancer. Med Phys 2010;37:5341-50.

[18] Gyenes G, Gagliardi G, Lax I, Fornander T, Rutqvist LE. Evaluation of irradiated heart volumes in stage I breast cancer patients treated with postoperative adjuvant radiotherapy. J Clin Oncol 1997;15:1348-53.

[19] Gyenes G, Rutqvist LE, Liedberg A, Fornander T. Long-term cardiac morbidity and mortality in a randomized trial of preand postoperative radiation therapy versus surgery alone in primary breast cancer. Radiother Oncol 1998;48:185-90.

[20] Evans SB, Sioshansi S, Moran MS, Hiatt J, Price LL, Wazer DE. Prevalence of poor cardiac anatomy in carcinoma of the breast treated with whole-breast radiotherapy: Reconciling modern cardiac dosimetry with cardiac mortality data. Am J Clin Oncol 2012;35:587-92.

[21] Hjelstuen MH, Mjaaland I, Vikström J, Dybvik KI. Radiation during deep inspiration allows loco-regional treatment of left breast and axillary-, supraclavicular- and internal mammary lymph nodes without compromising target coverage or dose restrictions to organs at risk. Acta Oncol 2012;51:333-44.

[22] Aznar MC, Korreman SS, Pedersen AN, Persson GF, Josipovic $M$, Specht L. Evaluation of dose to cardiac structures during breast irradiation. Br J Radiol 2011;84: 743-6.

[23] Chino JP, Marks LB. Prone positioning causes the heart to be displaced anteriorly within the thorax: Implications for breast cancer treatment. Int J Radiat Oncol Biol Phys 2008;70:916-20.

[24] Evans ES, Prosnitz RG, Yu X, Zhou SM, Hollis DR, Wong $\mathrm{TZ}$, et al. Impact of patient-specific factors, irradiated left ventricular volume, and treatment set-up errors on the development of myocardial perfusion defects after radiation therapy for left-sided breast cancer. Int J Radiat Oncol Biol Phys 2006;66:1125-34. 